\title{
O ESFORÇO INTELECTUAL ${ }^{1}$
}

\author{
Henri Bergson
}

Tradução: Jonas Gonçalves Coelho

O problema que abordamos aqui é distinto do problema da atenção tal como colocado pela psicologia contemporânea. Quando rememoramos fatos passados, quando interpretamos fatos presentes, quando ouvimos um discurso, quando seguimos o pensamento de alguém e quando escutamos o nosso próprio pensamento, enfim, quando um sistema complexo de representações ocupa nossa inteligência, nós sentimos que podemos tomar duas atitudes diferentes, uma de tensão e outra de relaxamento, que se distinguem sobretudo pela presença do sentimento de esforço em uma e pela sua ausência na outra. O jogo das representações é o mesmo nos dois casos? Os elementos intelectuais são da mesma espécie e mantêm entre si as mesmas relações? Não se encontraria na própria representação, nas suas reações interiores, na forma, no movimento e no agrupamento de estados mais simples que a compõem, tudo o que é necessário para distinguir o pensamento que se deixa viver do pensamento que se concentra e se esforça? Não faria

1 Este estudo apareceu na Revue philosophique de janeiro de 1902. Bergson desenvolve dois temas fundamentais de uma de suas mais importantes obras filosóficas, publicada cinco anos antes, Matéria e memória. Primeiramente, trata da relação entre percepção e memória, procurando destacar a íntima relação entre essas duas "operações elementares do espírito" nas mais distintas operações intelectuais de vigília, com ênfase especial no papel desempenhado pela memória, na existência de vários planos de memória e na noção de esquema, importante para a compreensão da "memória pura" bergsoniana. É o percurso entre os vários planos de memória a partir de esquemas que seria vivenciado como esforço intelectual presente nas atividades psíquicas de evocação, invenção e interpretação. A tensão psicológica característica dessas atividades psíquicas as diferencia das situações de relaxamento ou distensão características das vivências psíquicas do sonho e de livre associação da vigília nas quais o psiquismo operaria num único plano de memória.

2 Prof. Assistente Doutor de Filosofia do Departamento de Ciências Humanas da Unesp, campus de Bauru. 
parte do próprio sentimento de esforço a consciência de um movimento de representações muito particular? Tais são as questões que queremos colocar. Todas elas conduzem a uma única questão: Qual é a característica intelectual do esforço intelectual?

Independentemente da maneira pela qual se resolva essa questão, permanecerá intacto o problema da atenção, tal como colocado pelos psicólogos contemporâneos, preocupados, sobretudo, com a atenção sensorial, ou seja, com a atenção que prestamos a uma percepção simples. Ora, como a percepção simples, acompanhada de atenção, é uma percepção que poderia, em circunstâncias favoráveis, apresentar mais ou menos o mesmo conteúdo se a atenção não estivesse presente, é fora deste conteúdo que se teve de procurar o caráter específico da atenção. A idéia, proposta por M.Ribot, de atribuir uma importância decisiva aos fenômenos motores concomitantes, e sobretudo às ações de retenção, está muito perto de se tornar clássica em psicologia. Mas, à medida que o estado de concentração intelectual se complica, torna-se mais solidário do esforço que o acompanha. Existem trabalhos do espírito que não se concebe que se realizem cômoda e facilmente. Poder-se-ia, sem esforço, inventar uma nova máquina ou mesmo simplesmente extrair uma raiz quadrada? O estado intelectual traz, pois, impresso em si, de alguma maneira, a marca do esforço. O que significa novamente dizer que há uma característica intelectual do esforço intelectual. É verdade que, se esta característica existe para as representações de ordem complexa e elevada, deve também encontrar-se alguma coisa dela nos estados mais simples. Não é, pois, impossível que descubramos seus traços até na própria atenção sensorial, ainda que esse elemento tenha apenas um papel acessório e apagado.

Para simplificar nosso estudo, examinaremos separadamente as diversas espécies de trabalho intelectual, indo do mais fácil, que é a reprodução, ao mais difícil, que é a produção ou invenção. É pois com o esforço de memória, ou mais precisamente de evocação, que nos ocuparemos inicialmente.

\section{Os "planos de consciência"}

Mostramos, em um ensaio precedente, ${ }^{3}$ que é preciso distinguir uma série de "planos de consciência" diferentes, desde a "lembrança pura", ainda não traduzida em imagens distintas, até esta mesma lembrança atualizada em sensações nascentes e em movimentos iniciados. A evocação vo-

3 Matière et Mémoire, Paris, 1896, caps. 2 e 3. 
luntária de uma lembrança, dizíamos, consiste em atravessar esses planos de consciência um após o outro, em uma direção determinada. Ao mesmo tempo em que aparecia o nosso trabalho, M.S. Witasek publicava um artigo interessante e sugestivo, ${ }^{4}$ no qual a mesma operação era definida como "uma passagem do não intuitivo ao intuitivo". É voltando a alguns pontos do primeiro trabalho e também com o auxilio do segundo que estudaremos, inicialmente, no caso da evocação das lembranças, a diferença entre representação espontânea e representação voluntária.

Em geral, quando decoramos uma lição ou quando procuramos fixar um grupo de impressões em nossa memória, nosso único objetivo é reter bem o que aprendemos. Não nos preocupamos com o que teremos de fazer mais tarde para rememorar. O mecanismo da evocação nos é indiferente. $\mathrm{O}$ essencial é que possamos evocar a lembrança, não importa como, quando tivermos necessidade dela. Eis o motivo pelo qual empregamos, simultânea ou sucessivamente, os procedimentos mais diversos, utilizando tanto a memória maquinal quanto a memória inteligente, justapondo entre si as imagens auditivas, visuais e motoras para retê-las tais e quais no estado bruto, ou procurando substitui-las por uma idéia simples, que exprima o seu sentido e que permita, em tal caso, reconstituir-lhes a série. Eis por que, também, no momento da evocação, não recorremos exclusivamente à inteligência ou ao automatismo: automatismo e reflexão misturam-se intimamente, a imagem evocando a imagem ao mesmo tempo em que o espírito trabalha com as representações menos concretas. Daí a extrema dificuldade que experimentamos em definir com precisão a diferença entre as duas atitudes tomadas pelo espírito seja ao evocar maquinalmente todas as partes de uma lembrança complexa seja ao reconstituí-la ativamente. Há, quase sempre, uma parte de evocação mecânica e uma parte de reconstituição inteligente tão bem misturadas que não saberíamos dizer onde começa uma e onde termina a outra. Todavia, apresentam-se casos excepcionais nos quais se propõe a aprender uma lição complicada em vista de uma evocação instantânea e, tanto quanto possível, maquinal. Também existem casos nos quais se sabe que a lição a ser aprendida não terá jamais de ser lembrada de uma só vez; ao contrário, ela deverá ser objeto de uma reconstituição gradual e refletida. Examinemos inicialmente esses casos extremos. Veremos que procedemos diferentemente para reter dependendo da maneira pela qual evocaremos. Enquanto que, tendo adquirido a lembrança, o trabalho sui generis que se efetua para favorecer o esforço inteli-

4 Zeitschr. F. Psychologie, outubro 1896. 
gente de evocação ou para torná-lo inútil nos ensinará sobre a natureza e as condições deste esforço.

\section{A evocação sem esforço}

Em uma página curiosa de suas Confidences, Robert Houdin explica como procedeu para desenvolver em seu jovem filho uma memória intuitiva e instantânea. ${ }^{5}$ Ele começou mostrando à criança uma pedra de dominó, a cinco-quatro, perguntando o total de pontos, mas sem deixá-lo contar. A esta pedra acrescentou uma outra, a quatro-três, ainda exigindo uma resposta imediata. Ele encerrou aí a sua primeira lição. No dia seguinte, seu filho conseguiu somar, de uma só vez, três e, depois, quatro pedras. No outro dia, cinco pedras. Acrescentando a cada dia novos progressos aos do dia anterior, ele acabou obtendo, instantaneamente, a soma dos pontos de doze dominós. "Tendo conseguido este resultado, ocupamo-nos de um trabalho muito mais difícil, ao qual nos entregamos durante mais de um mês. Passávamos, meu filho e eu, bem rapidamente e com um olhar atento, diante de uma loja de brinquedos infantis ou de uma outra cheia de mercadorias variadas. A alguns passos dali, tirávamos lápis e papel do bolso e nos esforçávamos separadamente para escrever o nome do maior número de objetos que pudéssemos ter percebido durante a passagem... Meu filho chegava freqüentemente a escrever o nome de quarenta objetos..."

O objetivo dessa educação especial era colocar a criança em condições de perceber apenas com um golpe de vista, todos os objetos usados por todos os assistentes em uma sala de espetáculo. Então, com os olhos vendados, simulava a segunda-vista, descrevendo, a partir de um sinal convencional de seu pai, um objeto escolhido ao acaso por um dos espectadores. Esta memória visual foi desenvolvida a tal ponto que, após alguns instantes diante de uma biblioteca, a criança retinha um grande número de títulos e o lugar exato dos volumes correspondentes. O menino tirava, de algum modo, uma fotografia mental do todo, que permitia, em seguida, a evocação imediata das partes. Mas, desde a primeira lição, na proibição de adicionar entre si os pontos dos dominós, percebemos a mola principal dessa educação da memória. Toda interpretação da imagem visual era excluída do ato de visão: a inteligência era mantida no plano das imagens visuais.

É no plano das imagens auditivas ou das imagens de articulação que é preciso deixá-la para propiciar uma memória do mesmo gênero à audição. Entre os métodos propostos para o ensino das línguas, figura o de Prender-

5 Robert Houdin, Confidences, Paris, 1861, t.I, p.8 ss. 
gast ${ }^{6}$ cujo princípio tem sido muitas vezes utilizado. Ele consiste em fazer o aluno pronunciar inicialmente frases cujo significado não pode ser procurado. Nunca palavras isoladas, sempre proposições completas que ele precisa repetir maquinalmente. Se o aluno procurar adivinhar o sentido, compromete o resultado. Se há um momento de hesitação, tudo deve recomeçar. Variando o lugar das palavras, trocando palavras entre as frases, se faz com que, de algum modo, o sentido se destaque delas para a audição, sem que a inteligência aí se misture. O objetivo é obter da memória a evocação instantânea e fácil. E o artifício consiste em fazer com que o espírito evolua, o mais possível, entre as imagens de sons ou de articulações, sem que intervenham elementos mais abstratos, exteriores ao plano das sensações e dos movimentos.

A facilidade de evocação de uma lembrança complexa estaria, pois, na razão direta com a tendência de seus elementos se desenrolarem num mesmo plano de consciência. É o que cada um de nós pode observar em si mesmo. Um verso aprendido na escola permaneceu em nossa memória? Percebemos, ao recitá-lo, que a palavra chama a palavra e que uma reflexão sobre o sentido mais atrapalharia do que favoreceria o mecanismo de evocação. As lembranças, em tal caso, podem ser auditivas ou visuais, mas são sempre, ao mesmo tempo, motoras. É até mesmo difícil distinguir o que é lembrança auditiva e o que é hábito de articulação. Se nos detemos no meio da recitação, nosso sentimento do "incompleto" parece referir-se ora ao resto do verso que continua a cantar em nossa memória, ora ao movimento de articulação que não vai até o fim de seu élan e que gostaria de esgotá-lo, ora, e o mais freqüentemente, a um e ao outro ao mesmo tempo. Mas é preciso observar que estes dois grupos de lembranças - lembranças auditivas e lembranças motoras - são da mesma ordem, igualmente concretas, igualmente vizinhas da sensação. Elas estão, para retomar a expressão já empregada, no mesmo "plano de consciência".

Ao contrário, se a evocação é acompanhada de um esforço, é porque o espírito se move de um plano para outro.

\section{O esforço de evocação}

Como decorar quando não se pretende uma evocação instantânea? Os tratados de mnemotecnia o dizem e cada um de nós também o adivinha. Lê-se um trecho atentamente, depois se o divide em parágrafos ou seções

6 Prendergast, Handbook of the mastery series, Londres, 1868. 
considerando sua organização interior. Obtém-se, assim, uma visão esquemática do conjunto. Então, no interior do esquema, inserem-se as expressões mais relevantes. Ligam-se à idéia dominante as idéias subordinadas, às idéias subordinadas, as palavras dominadoras e representativas, a essas palavras, enfim, as palavras intermediárias que as ligam como em uma cadeia. Um tratado se exprime do seguinte modo: "O talento do mnemonista consiste em apreender em um trecho de prosa essas idéias salientes, essas frases curtas, essas simples palavras que carregam consigo as páginas inteiras". ${ }^{7}$ Um outro dá a regra seguinte: "Reduzir a fórmulas curtas e substanciais..., destacar em cada fórmula a palavra sugestiva..., associar estas palavras entre si e formar assim uma cadeia lógica de idéias". ${ }^{8}$ Nesse caso, não se liga mais mecanicamente imagens a imagens, cada uma restabelecendo a seguinte. Transporta-se para um ponto no qual a multiplicidade das imagens parece se condensar em uma representação única, simples e indivisa. É esta representação que se entrega à sua memória. Então, quando vier o momento da evocação, descer-se-á do cume da pirâmide para a base. Passar-se-á, do plano superior onde tudo estava reunido em uma única representação, a planos cada vez menos elevados, cada vez mais vizinhos da sensação, onde a representação simples está distribuída em imagens, onde as imagens se desdobram em frases e em palavras. É verdade que a evocação não mais será imediata e fácil. Ela será acompanhada pelo esforço.

Com este segundo método, é preciso, sem dúvida, mais tempo para se evocar, mas é preciso menos tempo para aprender. O aperfeiçoamento da memória, como observa-se muito freqüentemente, é menos um acréscimo de retenção que uma maior habilidade para subdividir, coordenar e encadear as idéias. O pregador, citado por W. James, levava inicialmente três ou quatro dias para decorar um sermão. Mais tarde, ele precisava apenas de dois, depois, de um só, finalmente, uma leitura única, atenta e analítica bastava. ${ }^{9} \mathrm{O}$ progresso aqui é evidentemente apenas uma aptidão crescente para fazer convergir todas as idéias, todas as imagens, todas as palavras para um único ponto. Trata-se de obter a peça única a partir da qual da qual todas as moedas são produzidas.

Qual é esta peça única? Como tantas imagens diversas estão contidas implicitamente em uma representação simples? Voltaremos a este ponto. Limitamo-nos no momento a dar à representação simples, desdobrável em imagens múltiplas, um nome que permita reconhecê-la. Diremos, apelando para o grego, que é um esquema dinâmico. Entendemos, assim, que esta

\footnotetext{
7 Audibert, Traité de mnémotechnie générale, Paris, 1840, p.173.

8 André, Mnémotechnie rationnelle, Angers, 1894.

9 W. James, Principles of Psychology, vol. I, p.667 (note).
} 
representação contém menos as próprias imagens que a indicação do que é preciso fazer para reconstituí-las. Não é um extrato das imagens que se obtém, empobrecendo cada uma delas. Se fosse, não se compreenderia como o esquema nos permite, em muitos casos, reencontrar as imagens integralmente. Não é também ou, pelo menos, não é somente, a representação abstrata do significado do conjunto das imagens. Sem dúvida, a idéia da significação ocupa nele um amplo espaço; mas, além de ser difícil dizer no que se torna esta idéia da significação das imagens quando se a destaca completamente das próprias imagens, é claro que a mesma significação lógica pode pertencer a séries de imagens muito diferentes e que ela não bastaria, por conseqüência, para nos fazer reter e reconstituir tal série de imagens estabelecida com a exclusão das outras. O esquema é alguma coisa difícil de se definir, mas algo cuja natureza cada um de nós sente e compreende ao comparar diversas espécies de memórias, sobretudo as memórias técnicas ou profissionais. Não podemos entrar aqui em detalhes. Diremos, no entanto, algumas palavras sobre uma memória que tem sido, nestes últimos anos, objeto de um estudo particularmente atento e penetrante, a memória dos jogadores de xadrez. ${ }^{10}$

\section{Intervenção de um esquema}

Sabe-se que alguns jogadores de xadrez são capazes de jogar simultaneamente várias partidas sem olhar os tabuleiros. Cada jogada de um de seus adversários lhe indica a nova posição da peça deslocada. Eles movem, então, uma peça de seu próprio jogo, e assim, jogando "às cegas", representando mentalmente, a todo o momento, as posições respectivas de todas as peças em todos os tabuleiros, eles chegam a vencer, freqüentemente, partidas simultâneas disputadas com hábeis jogadores. Em uma página bem conhecida de seu livro sobre a inteligência, Taine analisou esta aptidão, conforme as indicações fornecidas por um de seus amigos. ${ }^{11}$ Haveria aí, segundo ele, uma memória puramente visual. O jogador perceberia, o tempo todo, como em um espelho interior, a imagem de cada um dos tabuleiros com suas peças, tal como se apresentam após a última jogada.

Ora, da investigação realizada por M.Binet junto a um certo número de "jogadores às cegas" parece destacar-se uma conclusão muito clara: a imagem do tabuleiro com suas peças não se oferece à memória tal e qual, "como em um espelho", mas exige do jogador um esforço de reconstituição a

10 Binet, Psychologie des grands calculateurs e joueurs d'échecs, Paris, 1894.

11 Taine, De l'intelligence, Paris, 1870, t. I, p.81 ss. 
todo instante. Que esforço é este? Quais são os elementos efetivamente presentes na memória? É aqui que a investigação ofereceu resultados inesperados. Os jogadores consultados concordam, inicialmente, ao declarar que a visão mental das próprias peças lhes seria mais prejudicial que útil: o que retêm e representam de cada peça não é seu aspecto exterior, mas seu poder, seu alcance e seu valor, enfim, sua função. Um bispo não é um pedaço de madeira de forma mais ou menos bizarra: é uma "força oblíqua". A torre é uma certa potência de "mover em linha reta", o cavalo é "uma peça que equivale mais ou menos a três piões e que se move segundo uma lei muito particular", etc. Isso para as peças. Considere-se agora a partida. O que está presente no espírito do jogador é uma composição de forças, ou melhor, uma relação entre potências aliadas ou hostis. O jogador refaz mentalmente a história da partida desde o início. Ele reconstitui os acontecimentos sucessivos que conduziram à situação atual. Ele obtém, assim, uma representação do todo que lhe permite, em um momento qualquer, visualizar os elementos. Esta representação abstrata é, aliás, una. Ela implica uma penetração recíproca de todos os elementos uns nos outros. O que o prova é que cada partida aparece ao jogador com uma fisionomia própria. Ela lhe provoca uma impressão sui generis. "Eu a apreendo em conjunto como um músico apreende um acorde", diz um dos personagens consultados. E é justamente esta diferença de fisionomia que permite reter várias partidas sem confundi-las. Há, pois, também, um esquema representativo do todo, e este esquema não é nem um extrato, nem um resumo. Ele é tão completo quanto o será a imagem, caso ela seja ressuscitada, mas ele contém em estado de implicação recíproca o que a imagem desdobrará em partes exteriores umas às outras.

Analisem o esforço que vocês fazem quando evocam com dificuldade uma lembrança simples. Vocês partem de uma representação na qual sentem que estão dados um no outro elementos dinâmicos muito diferentes. Esta implicação recíproca e, conseqüentemente, esta complicação interior, é algo tão necessário, tão essencial na representação esquemática, que o esquema poderá, se a imagem a evocar for simples, ser muito menos simples que ela. Não preciso ir muito longe para encontrar um exemplo disso. Há algum tempo, ao colocar no papel o plano do presente artigo e preparar a lista dos trabalhos a serem consultados, eu queria escrever o nome Prendergast, o autor cujo método intuitivo citei há pouco e cujas publicações li outrora junto com muitas outras sobre a memória. Mas eu não conseguia nem encontrar esse nome, nem evocar a obra na qual eu o vi inicialmente citado. Anotei as fases do trabalho no qual eu tentava evocar o nome recalcitrante. Parti da impressão geral que dele me restava. Era uma impressão de estranheza, mas não de estranheza indeterminada. Havia algo como um sinal dominante de barbárie, de rapina, o sentimento que poderia ter sido 
causado por uma ave agarrando sua vítima, comprimindo-a em suas garras e levando-a consigo. Digo agora que a palavra prendre, que era mais ou menos figurada pelas duas primeiras sílabas do nome procurado, participava em larga medida de minha impressão. Mas eu não sabia se esta semelhança bastaria para determinar uma nuança de sentimento tão preciso. Vendo com que obstinação o nome "Arbogaste" se apresenta hoje ao meu espírito quando penso em "Prendergast", pergunto-me se eu não tinha fundido ao mesmo tempo a idéia geral de "prendre" e o nome Arbogaste. Este último nome, que me restou do tempo em que aprendi a história romana, evocava em minha memória vagas imagens de barbárie. Todavia, não estou seguro disso, e tudo o que posso afirmar é que a impressão deixada em meu espírito era absolutamente sui gereris, e que ela tendia, por meio de mil dificuldades, a se transformar em nome próprio. Sobretudo as letras $d$ e $r$ eram trazidas à minha memória por esta impressão. Mas elas não eram trazidas como imagens visuais ou auditivas, ou mesmo como imagens motoras completamente prontas. Elas se apresentavam sobretudo indicando uma certa direção de esforço a seguir para chegar à articulação do nome procurado. Parecia-me, equivocadamente aliás, que essas letras deviam ser as primeiras da palavra, justamente porque pareciam me mostrar um caminho. Eu dizia a mim mesmo que, tentando com as diversas vogais alternadamente, eu conseguiria pronunciar a primeira sílaba e adquirir, assim, um élan que me levaria até o fim da palavra. Este trabalho foi concluído? Eu não sei, mas ele não estava ainda muito adiantado, quando, bruscamente, me veio ao espírito que o nome era citado em uma nota do livro de Kay sobre a educação da memória, e que foi aí que tomei conhecimento dele. É ali que eu iria imediatamente procurá-lo. Talvez a ressurreição súbita da lembrança útil fosse efeito do acaso. Mas talvez também o trabalho destinado a converter o esquema em imagem tivesse ultrapassado seu fim, evocando, então, em lugar da própria imagem, as circunstâncias que a cercaram primitivamente.

\section{Desdobramento em imagens}

Nesses exemplos, a essência do esforço de memória parece consistir em desdobrar um esquema senão simples, pelo menos concentrado, em uma imagem com elementos distintos e mais ou menos independentes uns dos outros. Quando deixamos nossa memória vagar ao acaso, sem esforço, as imagens sucedem às imagens, todas elas situadas no mesmo plano de consciência. Ao contrário, desde que nos esforcemos para lembrar, parece que nos concentramos em um estágio superior para descer em seguida, progressivamente, para as imagens a evocar. Se, no primeiro caso, associando imagens a imagens, nos movemos com um movimento que chama- 
remos, por exemplo, horizontal, num plano único, devemos dizer que no segundo caso o movimento é vertical, e que ele nos faz passar de um plano para outro. No primeiro caso, as imagens são homogêneas entre si, mas representativas de objetos diferentes. No segundo, um único e mesmo objeto é representado em todos os momentos da operação, mas ele o é diferentemente, pelos estados intelectuais heterogêneos entre si, ora esquemas ora imagens, o esquema tendendo para a imagem na medida em que o movimento de descida se acentua. Enfim, cada um de nós tem o sentimento muito nítido de uma operação que prosseguiria em extensão e em superfície em um caso e, em intensidade e profundidade, no outro.

É raro, aliás, que as duas operações se realizem isoladamente e que se as encontre em estado puro. A maior parte dos atos de evocação compreendem ao mesmo tempo uma descida do esquema para a imagem e um passeio entre as próprias imagens. Mas isto quer dizer, como o indicamos no início deste estudo, que um ato de memória contém ordinariamente uma parte de esforço e uma de automatismo. Penso neste momento em uma longa viagem que fiz outrora. Os incidentes dessa viagem retornam ao meu espírito em uma ordem qualquer, evocando mecanicamente uns aos outros. Mas se me esforço para rememorar tal ou qual período, vou do todo do período às partes que o compõem, o todo me aparecendo inicialmente como um esquema indiviso, com uma certa coloração afetiva. Freqüentemente, aliás, as imagens, após terem simplesmente jogado entre si, solicitam que eu recorra ao esquema para completá-las. Mas é no trajeto do esquema à imagem que sinto o esforço.

Concluamos por enquanto que o esforço de evocação consiste em converter uma representação esquemática, cujos elementos se interpenetram, em uma representação imagética cujas partes se justapõem.

\section{O esforço intelectual}

É preciso estudar agora o esforço de intelecção em geral, aquele que fazemos para compreender e para interpretar. Limitar-me-ei, aqui, a indicações, remetendo o restante a um trabalho anterior. ${ }^{12}$

$\mathrm{O}$ ato de intelecção realiza-se sem cessar. É difícil dizer onde começa e onde termina o esforço intelectual. Todavia, há uma certa maneira de compreender e de interpretar que exclui o esforço, e há uma outra que, sem o implicar necessariamente, pode ser geralmente observada quando ele está presente.

12 Matière et Mémoire, pp.89-141. 
A intelecção do primeiro gênero é a que consiste em responder automaticamente, por um ato apropriado, a uma percepção mais ou menos complexa. O que é reconhecer um objeto usual senão saber dele se servir? E o que é "saber dele se servir" senão esboçar maquinalmente, quando se o percebe, a ação que o hábito associou a esta percepção? Sabe-se que os primeiros observadores deram o nome de apraxia à cegueira psíquica, exprimindo, assim, que a inaptidão em reconhecer os objetos usuais é sobretudo uma impotência de os utilizar. ${ }^{13}$ Esta intelecção automática estende-se muito mais longe do que se imagina. A conversação corrente compõe-se, em grande parte, de respostas prontas a questões banais, a resposta sucedendo à questão sem que a inteligência se interesse pelo sentido de uma e de outra. É assim que os dementes mantêm uma conversação mais ou menos coerente sobre um assunto simples, embora não saibam o que dizem. ${ }^{14}$ Foi muitas vezes observado que podemos ligar palavras a palavras, regulando-nos pela compatibilidade ou incompatibilidade, por assim dizer, musical dos sons entre si e, desse modo, compor frases que funcionam sem que a inteligência propriamente dita se misture. Nestes exemplos, a interpretação das sensações ocorre imediatamente por movimentos. O espírito permanece, como o dizíamos, num único e mesmo "plano de consciência".

A intelecção verdadeira é totalmente distinta. Ela consiste em um movimento do espírito que vai e vem entre as percepções ou as imagens, por um lado, e sua significação, por outro. Qual é a direção essencial desse movimento? Poder-se-ia acreditar que partimos das imagens para remontar à sua significação, visto que as imagens são dadas primeiro, e que "compreender" consiste, em suma, em interpretar percepções ou imagens. Quer se trate de seguir uma demonstração, de ler um livro, de ouvir um discurso, são sempre percepções ou imagens que seriam apresentadas à inteligência para serem traduzidas por ela em relações, como se ela devesse ir do concreto ao abstrato. Mas isso é apenas uma aparência. É fácil ver que o espírito faz, de fato, o inverso no trabalho de interpretação.

Isso é evidente no caso de uma operação matemática. Podemos seguir um cálculo sem o refazermos nós próprios? Compreendemos a solução de um problema sem o resolvermos nós mesmos? O cálculo é escrito no quadro, a solução é impressa em um livro ou apresentada à viva voz, mas as cifras que vemos são apenas as marcas indicadoras às quais nos reportamos

13 Kussmaul, Les troubles de la parole, Paris, 1884, p.233; Allen Starr, Aprazia and Aphasia, Medical Record, outubro 1888. Cf. Laquer, Neurolog. Centralblatt, junho 1888; Nodet, Les agnoscies, Paris, 1899; e Claparède, Revue génerale sur l'agonosie, Année psychologique, VI, 1900, p.85 ss.

14 Robertson, Reflex Speech, Journal of mental Science, abril 1888; Fére, Le langage réflexe, Revue philosophique, janeiro 1896. 
para assegurar que não nos desviamos do caminho. As frases que lemos ou ouvimos só têm um sentido completo quando somos capazes de as reencontrar por nós mesmos, de as criar de novo, por assim dizer, tirando do fundo de nos mesmos a expressão da verdade matemática que elas ensinam. Ao longo da demonstração vista ou ouvida, colhemos algumas sugestões, escolhemos pontos de referência. Dessas imagens visuais ou auditivas, saltamos para representações abstratas de relação. Partindo dessas representações, as desdobramos em palavras imaginadas que vêm reunir-se e recobrir as palavras lidas ou ouvidas.

Mas não acontece o mesmo com todo trabalho de interpretação? Raciocina-se algumas vezes como se ler e escutar consistisse em se apoiar nas palavras vistas ou ouvidas para se elevar de cada uma delas à idéia correspondente, e justapor em seguida estas diversas idéias entre si. O estudo experimental da leitura e da audição das palavras nos mostra que as coisas se passam de uma maneira inteiramente diferente. Inicialmente, o que vemos de uma palavra na leitura corrente se reduz a muito pouca coisa: algumas letras - menos que isto, algumas hastes ou traços característicos. As experiências de Cattell, de Goldscheider e Müller, de Pillsbury (criticadas, é verdade, por Erdmann e Lodge) parecem concludentes nesse ponto. Não menos instrutivas são as experiências de Bagley sobre a audição da palavra. Elas estabelecem com precisão que ouvimos apenas uma parte das palavras pronunciadas. Mas, independentemente de toda experiência científica, cada um de nós pôde constatar a impossibilidade de perceber distintamente as palavras de uma língua que não se conhece. A verdade é que a visão e a audição bruta limitam-se, em tal caso, a nos fornecer pontos de referência, ou melhor, a nos traçar um quadro, que preenchemos com nossas lembranças. Seria enganar-se excessivamente sobre o mecanismo do reconhecimento acreditar que começamos por ver e por ouvir, e que em seguida, com a percepção já constituída, a aproximamos de uma lembrança semelhante para reconhecê-la. A verdade é que a lembrança nos faz ver e ouvir e a percepção seria incapaz, por si mesma, de evocar a lembrança parecida com ela, visto que seria preciso, para isto, que ela tivesse já tomado forma e fosse suficientemente completa. Ora ela só se torna percepção completa e só adquire uma forma distinta pela própria lembrança, a qual se insinua nela e lhe fornece a maior parte de sua matéria. Mas, se é assim, é preciso que seja o sentido, antes de tudo, que nos guie na reconstituição das formas e dos sons. O que vemos da frase lida, o que ouvimos da frase pronunciada, é exatamente o que é necessário para nos colocar na ordem de idéias correspondente. Então, partindo das idéias, isto é, das relações abstratas, nós as materializamos imaginativamente em palavras hipotéticas que tentam colocar-se sobre o que vemos e ouvimos. A interpretação é, pois, em realidade, uma reconstrução. Um primeiro contato com a imagem 
imprime ao pensamento abstrato sua direção. Este se desenvolve, em seguida, em imagens representadas, que tomam contato, por sua vez, com imagens percebidas, seguindo seus traços, esforçando-se para recobri-las. Onde a superposição é perfeita, a percepção é completamente interpretada.

Este trabalho de interpretação é muito fácil, quando ouvimos nossa própria língua, para que tenhamos tempo de decompô-lo em suas diversas fases. Mas temos consciência nítida dele quando conversamos em uma língua estrangeira que conhecemos imperfeitamente. Nesse caso, damos-nos conta de que os sons ouvidos distintamente nos servem de pontos de referência, que nos colocamos inicialmente em uma ordem de representações mais ou menos abstrata, sugerida pelo que ouvimos, e que uma vez adotado este ton intelectual, vamos do sentido concebido ao reencontro dos sons percebidos. É preciso, para que a interpretação seja exata, que a junção se opere.

Concebe-se que a interpretação seja possível, se fôssemos realmente das palavras às idéias? As palavras de uma frase não têm um sentido absoluto. Cada uma delas empresta uma nuança de significação particular à precedente e à seguinte. As palavras de uma frase não são também todas capazes de evocar uma imagem ou uma idéia independentes. Muitas dentre elas exprimem relações, e as exprimem apenas por seu lugar no conjunto e por sua ligação com as outras palavras da frase. Uma inteligência que fosse, sem cessar, da palavra à idéia, estaria constantemente embaraçada e, seria por assim dizer, errante. A intelecção só pode ser precisa e segura se partimos do sentido suposto, reconstruído hipoteticamente, se descemos daí aos fragmentos das palavras realmente percebidas, se nos regulamos por elas sem cessar e se nos servimos delas como simples balizas para desenhar, em todas as suas sinuosidades, a curva especial da rota que a inteligência seguirá.

Não posso abordar aqui o problema da atenção sensorial. Mas creio que a atenção voluntária, aquela que se acompanha ou que pode se acompanhar de um sentimento de esforço, difere da atenção maquinal precisamente pelo fato de acionar elementos psicológicos situados em planos de consciência diferentes. Na atenção maquinal, existem movimentos e atitudes favoráveis à percepção distinta, que respondem ao apelo da percepção confusa. Mas não parece que haja jamais atenção voluntária sem uma "pré-percepção", como dizia Lewes, ${ }^{15}$ isto é, sem uma representação que seja ora uma imagem antecipada, ora alguma coisa mais abstrata, uma hipótese relativa à significação daquilo que se vai perceber e à relação provável dessa percepção com alguns elementos da experiência passada.

15 Lewes, Problems of Life and Mind, Londres, 1879, t.III, p.106. 
Tem-se discutido sobre o sentido verdadeiro das oscilações da atenção. Uns atribuem ao fenômeno uma origem central, outros uma origem periférica. Mas, mesmo que não se aceite a primeira tese, parece que é preciso reter dela alguma coisa e admitir que a atenção não acontece sem uma certa projeção excêntrica de imagens que descem para a percepção. Explicar-se-ia, assim, o efeito da atenção, que é ou intensificar a imagem, como sustentam alguns autores, ou, pelo menos, torná-la mais clara e mais distinta. Compreender-se-ia o enriquecimento gradual da percepção pela atenção, se a percepção bruta não fosse um simples meio de sugestão, um apelo lançado sobretudo à memória? A percepção bruta de certas partes sugere uma representação esquemática do conjunto e, por aí, relações das partes entre si. Desenvolvendo este esquema em imagens-lembranças, procuramos fazer coincidir estas imagens-lembranças com as imagens percebidas. Se não o conseguimos, transportamo-nos para uma outra representação esquemática. E sempre a parte positiva, útil, desse trabalho, consiste em ir do esquema à imagem percebida.

O esforço intelectual para interpretar, compreender, prestar atenção, é, pois, um movimento do "esquema dinâmico" na direção da imagem que o desenvolve. É uma transformação contínua de relações abstratas, sugeridas pelos objetos percebidos, em imagens concretas, capazes de recobrir esses objetos. Sem dúvida, o sentimento de esforço não se produz sempre nessa operação. Ver-se-á, a seguir, que condição particular é satisfeita quando o esforço a ela se junta. Mas é somente no curso de um desenvolvimento desse gênero que temos consciência de um esforço intelectual. $O$ sentimento de esforço de intelecção se produz no trajeto do esquema à imagem.

\section{O esforço de invenção}

Resta verificar essa lei nas formas mais altas do esforço intelectual: falo do esforço de invenção. Como observou M.Ribot, criar imaginativamente é resolver um problema. ${ }^{16}$ Ora, como resolver um problema senão supondo-o inicialmente resolvido? Representa-se, diz M.Ribot, um ideal, isto é, um certo efeito obtido, procura-se, então, por meio de qual composição de elementos obter-se-á este efeito. Transporta-se de um salto ao resultado completo, ao fim que se trata de realizar. Todo esforço de invenção é uma tentativa de preencher o intervalo por cima do qual se saltou e chegar novamente a este mesmo fim, só que agora seguindo o fio contínuo dos meios que o realizarão. Mas como perceber o fim sem os meios, o todo sem as partes?

16 Ribot, L'imagination créatrice, 1900, p.130. 
Não pode ser sob a forma de imagem, visto que uma imagem que nos faria ver o efeito realizando-se nos mostraria, interiores a essa mesma imagem, os meios pelos quais o efeito se realiza. Forçoso é, pois, admitir que o todo se oferece como um esquema, e que a invenção consiste precisamente em converter o esquema em imagem.

O inventor que quer construir uma certa máquina representa-se o trabalho a obter. A forma abstrata desse trabalho evoca sucessivamente em seu espírito, à força de tateamentos e experiências, a forma concreta dos diversos movimentos componentes que realizariam o movimento total, as peças e combinações de peças capazes de realizar esses movimentos parciais. A invenção tomou corpo precisamente nesse momento, a representação esquemática tornou-se representação imagética. O escritor que escreve um romance, o autor dramático que cria personagens e situações, o músico que compõe uma sinfonia e o poeta que compõe uma ode, todos eles têm inicialmente no espírito alguma coisa simples e abstrata, isto é, incorpórea. É, para o músico ou poeta, uma impressão nova que se trata de desenvolver em sons ou em imagens. É, para o romancista ou o dramaturgo, uma tese a desenvolver em acontecimentos, um sentimento, individual ou social, a materializar em personagens vivos. Trabalha-se sobre um esquema do todo, e o resultado é obtido quando se chega a uma imagem distinta dos elementos. M.Paulhan mostrou, com exemplos do mais alto interesse, como a invenção literária e poética vai "do abstrato ao concreto", em suma, do todo às partes e do esquema à imagem. ${ }^{17}$

Além disso é preciso que o esquema permaneça imutável durante a operação. Ele é modificado pelas próprias imagens com as quais procura se preencher. Por vezes não resta mais nada do esquema primitivo na imagem definitiva. À medida que o inventor realiza os detalhes de sua máquina, ele renuncia a uma parte do que queria dela obter ou obtém outra coisa. Do mesmo modo, os personagens criados pelo romancista e pelo poeta reagem à idéia ou ao sentimento que eles estão destinados a exprimir. Aí está, sobretudo, a parte do imprevisto. Ela está, poder-se-ia dizer, no movimento pelo qual a imagem retorna ao esquema para modificá-lo ou fazê-lo desaparecer. Mas o esforço propriamente dito está no trajeto do esquema, invariável ou variável, às imagens que o devem preencher.

É necessário também que o esquema preceda sempre à imagem explicitamente. M.Ribot mostrou que seria preciso distinguir duas formas de imaginação criadora, uma intuitiva e outra refletida. "A primeira vai da unidade aos detalhes..., a segunda vai dos detalhes à unidade vagamente en-

17 Paulhan, Psychologie de l'invention, Paris, 1901, cap.4. 
trevista. Ela inicia-se por um fragmento que serve de chamariz e se completa pouco a pouco... Kepler consagrou uma parte de sua vida a hipóteses bizarras até o dia em que, tendo descoberto a órbita elíptica de Marte, todo o seu trabalho anterior tomou corpo e organizou-se em sistema. ${ }^{18}$ "Em outros termos, em lugar de um esquema único, de formas imóveis e rígidas, do qual se tem uma concepção distinta, pode haver um esquema elástico ou movente, cujos contornos o espírito se recusa a fixar, porque espera sua decisão das próprias imagens que o esquema deve atrair para se dar um corpo. Mas, seja o esquema fixo ou móvel, é durante seu desenvolvimento em imagens que surge o sentimento de esforço intelectual.

Aproximando essas conclusões das precedentes, chegar-se-á a uma fórmula do trabalho intelectual, isto é, do movimento do espírito que pode, em certos casos, acompanhar-se de um sentimento de esforço: Trabalhar intelectualmente consiste em conduzir uma mesma representação através de planos de consciência diferentes em uma direção que vai do abstrato ao concreto, do esquema à imagem. Resta saber em quais casos especiais esse movimento do espírito (que talvez envolva sempre um sentimento de esforço, mas freqüentemente muito leve ou muito familiar para ser percebido distintamente) nos dá a consciência nítida de um esforço intelectual.

\section{Trabalho do esquema e das imagens}

A esta questão, o simples bom senso responde que há esforço, mais trabalho, quando o trabalho é difícil. Mas qual é o sinal pelo qual se reconhece a dificuldade do trabalho? É quando o trabalho "não se realiza por si só", quando se experimenta um embaraço, quando se depara com um obstáculo, enfim, quando ele leva mais tempo do que se gostaria para alcançar o fim. Quem diz esforço diz lentidão e atraso. Além disso, poder-se-ia instalar-se no esquema e esperar indefinidamente a imagem, poder-se-ia retardar indefinidamente o trabalho, sem se ter a consciência de um esforço. É preciso, pois, que o tempo de espera seja preenchido de uma certa maneira, isto é, que uma diversidade muito particular de estados nele se sucedam. Quais são estes estados? Sabemos que há movimento do esquema às imagens e que o espírito trabalha apenas na conversão do esquema em imagens. Os estados pelos quais ele passa correspondem, pois, às tantas tentativas de inserir as imagens no esquema, ou ainda, em certos casos pelo menos, às modificações aceitas pelo esquema para obter a tradução em imagens. Nessa hesitação muito especial deve encontrar-se a característica do esforço intelectual.

18 Ribot, op.cit., p.133. 
O que posso fazer melhor aqui é retomar, adaptando às considerações que se acaba de ler, uma idéia interessante e profunda apresentada por M.Dewey em seu estudo sobre a psicologia do esforço. ${ }^{19}$ Haveria esforço, segundo M.Dewey, todas as vezes que nos servimos dos hábitos adquiridos para a aprendizagem de um novo exercício. Mais particularmente, se se trata de um exercício físico, só podemos aprendê-lo utilizando ou modificando alguns movimentos aos quais já estamos acostumados. Mas o antigo hábito está aí, ele resiste ao novo hábito que queremos adquirir por meio dele. O esforço apenas manifesta essa luta dos dois hábitos, ao mesmo tempo diferentes e semelhantes.

Exprimamos essa idéia em função de esquemas e de imagens. Apliquemos esta nova forma ao esforço corporal, aquele com o qual o autor tem principalmente se preocupado, e vejamos se o esforço corporal e o esforço intelectual não se elucidariam um ao outro.

Como procedemos para aprender sozinhos um exercício complexo, tal como a dança? Começamos olhando a dança. Obtemos, assim, uma percepção visual do movimento da valsa, se é da valsa que se trata. Confiamos esta percepção à nossa memória. A partir daí nosso objetivo é obter de nossas pernas os movimentos cuja impressão assemelha-se, a nosso ver, àquela guardada em nossa memória. Mas qual era esta impressão? Diremos que é uma imagem nítida, definitiva, perfeita, do movimento da valsa? Falar assim seria admitir que se pode perceber exatamente o movimento da valsa quando não se sabe valsar. Ora, é bem evidente que, se para aprender esta dança, é preciso começar vendo-a em execução, inversamente, só se vê bem, em seus detalhes e mesmo em seu conjunto, quando já se está habituado a dançá-la. A imagem da qual nos servimos não é, pois, uma imagem visual fixa: não é uma imagem fixa, visto que ela mudará e tornar-se-á precisa no curso da aprendizagem que ela está encarregada de dirigir. E ela não é mais uma imagem completamente visual, porque se ela se aperfeiçoa no curso da aprendizagem, isto é, na medida em que adquirimos as imagens motoras apropriadas, é porque as imagens motoras, evocadas por ela e mais precisas que ela, a invadem e tendem até mesmo a suplantá-la. Para dizer a verdade, a parte útil dessa representação não é nem puramente visual nem puramente motora. É uma e outra ao mesmo tempo, o desenho de relações, sobretudo temporais, entre as partes sucessivas do movimento a ser executado. Uma representação desse gênero, na qual estão figuradas sobretudo as relações, parece muito com o que chamávamos de esquema.

Mas só saberemos dançar no dia em que esse esquema, suposto completo, obtiver de nosso corpo os movimentos sucessivos que ele propõe

19 Dewey, The psychology of effort, Philosophical Review, janeiro 1897. 
como modelo. Em outros termos, o esquema, representação cada vez mais abstrata do movimento a executar, deverá ser preenchido com todas as sensações motoras que correspondem ao movimento se executando. Ele só pode fazê-lo evocando uma a uma as representações dessas sensações ou, para falar como Bastian, as "imagens kinestésicas" dos movimentos parciais, elementares, compondo o movimento total. Essas lembranças de sensações motoras, à medida que revivem, convertem-se em sensações motoras reais e, conseqüentemente, em movimentos executados. Mas ainda é preciso que possuamos essas imagens motoras. O que quer dizer que, para contrair o hábito de um movimento complexo como o da valsa, é preciso ter já o hábito dos movimentos elementares nos quais a valsa se decompõe. De fato, é fácil ver que os movimentos que realizamos ordinariamente para andar, para nos erguer na ponta dos pés, para nos girarmos, são aqueles que utilizamos para aprender a valsar. Mas não os utilizamos tais e quais. É preciso modificá-los mais ou menos, infletir cada um deles na direção do movimento geral da valsa, sobretudo, combiná-los de uma maneira nova. Há, pois, de um lado, a representação esquemática do movimento total e novo, de outro, as imagens kinestésicas de movimentos antigos, idênticos ou análogos aos movimentos elementares nos quais o movimento total foi analisado. A aprendizagem da valsa consistirá em obter dessas imagens kinestésicas diversas, já antigas, uma nova sistematização que lhes permita inserir simultaneamente no esquema. Trata-se, ainda, aqui de desenvolver um esquema em imagens. Mas o agrupamento antigo luta contra o agrupamento novo. O hábito de andar, por exemplo, contraria a tentativa de dançar. A imagem kinestésica total do andar impede-nos de constituir, em seguida, com as imagens kinestésicas elementares do andar e algumas outras, a imagem kinestésica total da dança. O esquema da dança não é preenchido imediatamente com as imagens apropriadas. O atraso causado pela necessidade que o esquema tem de conduzir gradualmente as imagens múltiplas elementares a um novo modus vivendi, ocasionado também, em muitos casos, pelas modificações trazidas ao esquema para que se o desenvolva em imagens - esse atraso sui generis que é feito de tateamentos, de tentativas mais ou menos frutuosas, de adaptações das imagens ao esquema e do esquema às imagens, de interferências ou de superposições das imagens entre si - este atraso não mede o intervalo entre a tentativa penosa e a execução fácil, entre a aprendizagem de um exercício e o próprio exercício?

\section{Sentimento de esforço}

Ora, é fácil ver que isso também acontece com o esforço para aprender e para compreender, em suma, com todo esforço intelectual. Trata-se do es- 
forço da memória? Mostramos que ele se produz na transição do esquema à imagem. Mas há casos nos quais o desenvolvimento do esquema em imagem é imediato, porque uma só imagem se apresenta para preencher esse fim. E há outros nos quais as imagens múltiplas e análogas se apresentam concorrentemente. Em geral, quando várias imagens diferentes estão entre as concorrentes, é porque nenhuma delas satisfaz inteiramente as condições do esquema. Eis por que, em tal caso, o esquema pode ter que se modificar para obter o desenvolvimento em imagens. Assim, quando quero rememorar um nome próprio, dirijo-me primeiro à impressão geral que dele guardei. É ela que desempenhará o papel de "esquema dinâmico". Logo, diversas imagens elementares, correspondendo, por exemplo, a algumas letras do alfabeto, apresentam-se ao meu espírito. Essas letras procuram ou compor-se conjuntamente ou substituir umas às outras, ou seja, a organizar-se segundo as indicações do esquema. Mas, freqüentemente, no curso desse trabalho, revela-se a impossibilidade de se chegar a uma forma de organização viável. Daí uma modificação gradual do esquema, é exigida pelas próprias imagens que suscitou, as quais podem muito bem ter de se transformar ou mesmo desaparecer. Mas, quer as imagens se arranjem simplesmente entre si, quer esquema e imagem tenham de se fazer concessões recíprocas, o esforço de evocação implica sempre um afastamento seguido de uma aproximação gradual entre o esquema e as imagens. Quanto mais essa aproximação exige idas e vindas, oscilações, lutas e negociações, mais se acentua o sentimento de esforço.

Em nenhuma parte, esse jogo é tão visível quanto no esforço de invenção. Nesse caso, temos o sentimento nítido de uma forma de organização, variável sem dúvida, mas anterior aos elementos que devem se organizar, depois de uma concorrência entre si, ou seja, quando a invenção culmina em um equilíbrio que é uma adaptação recíproca entre a forma e a matéria. O esquema varia de tempos em tempos, mas em cada um dos períodos ele permanece relativamente fixo, e são as imagens que devem se ajustar a ele. Tudo se passa como se um pedaço de borracha fosse puxado em vários sentidos ao mesmo tempo para que tomasse a forma geométrica de um polígono qualquer. Em geral, a borracha se encurta em alguns pontos à medida que se alonga em outros. É preciso retomá-la, fixar o resultado obtido a cada passo. Durante esta operação, ainda pode-se ter de modificar a forma estabelecida inicialmente para o polígono. Acontece o mesmo com o esforço de invenção, quer ele dure alguns segundos, quer exija anos.

Mas este vai e vem entre esquema e imagens, esse jogo das imagens compondo-se ou lutando entre si para entrar no esquema, enfim, esse movimento sui generis de representações é parte integrante de nosso sentimento de esforço? Se está presente sempre que experimentamos o sentimento de esforço intelectual, se está ausente quando falta esse sentimento, 
pode-se admitir que não tenha qualquer participação no próprio sentimento? Mas, por outro lado, como um jogo de representações, um movimento de idéias, poderia fazer parte da composição de um sentimento? A psicologia contemporânea inclina-se a reduzir a sensações periféricas tudo o que há de afetivo na afecção. E, mesmo que não se vá tão longe, parece que a afecção é irredutível à representação. Qual é exatamente a relação entre a nuança afetiva que colore todo esforço intelectual e o jogo particular de representações que a análise nele descobre?

Não teremos qualquer dificuldade em reconhecer que, na atenção, na reflexão, no esforço intelectual em geral, a afecção experimentada pode se reduzir a sensações periféricas. Mas não se segue daí que o "jogo de representações", assinalado por nós como característico do esforço intelectual, não se faça sentir nessa afecção. Basta admitir que o jogo de sensações responde ao jogo de representações e lhe faz eco, por assim dizer, em um outro tom. É muito fácil compreender que não se trata, aqui, em realidade, de uma representação, mas de um movimento de representações, de uma luta ou de uma interferência das representações entre si. Concebe-se que estas oscilações mentais tenham suas harmônicas sensoriais. Concebe-se que esta indecisão da inteligência prolongue-se em uma inquietude do corpo. As sensações características do esforço intelectual exprimiriam esta suspensão e esta inquietude. De maneira geral, não se poderia dizer que as sensações periféricas que a análise descobre em uma emoção são sempre mais ou menos simbólicas das representações às quais esta emoção se liga e das quais ela deriva? Tendemos a representar exteriormente nossos pensamentos, e a nossa consciência dessa representação, realizando-se, retorna, por uma espécie de ricochete, ao próprio pensamento. Daí a emoção, que tem ordinariamente por centro uma representação, mas na qual são sobretudo visíveis as sensações nas quais esta representação se prolonga. Sensações e representação estão aliás em uma continuidade tão perfeita que não se saberia dizer onde uma termina e onde as outras começam. Eis por que a consciência, colocando-se no meio e fazendo uma média, erige o sentimento em estado sui generis, intermediário entre a sensação e a representação. Mas limitar-nos-emos a indicar esta via sem nela nos deter. $\mathrm{O}$ problema que colocamos aqui não pode ser resolvido de uma maneira satisfatória no estado atual da ciência psicológica.

\section{Resultado do esforço}

Resta-nos, para concluir, mostrar que esta concepção do esforço mental dá conta dos principais efeitos do trabalho intelectual, e que ela é ao 
mesmo tempo aquela que mais se aproxima da constatação pura e simples dos fatos, aquela que menos se parece com uma teoria.

Reconhece-se que o esforço dá à representação uma clareza e uma distinção superiores. Ora, uma representação é tanto mais clara quanto nela se realça um maior número de detalhes, e é tanto mais distinta quanto melhor isolada e diferenciada de todas as outras. Se o esforço mental consiste em uma série de ações e de reações entre um esquema e as imagens, compreende-se que este movimento interior acabe, por um lado, por isolar melhor a representação, e, por outro, por enriquecê-la mais. A representação isola-se de todas as outras, porque o esquema organizador rejeita as imagens que não são capazes de o desenvolver, e confere, assim, uma individualidade verdadeira ao conteúdo atual da consciência. E, além disso, ela se preenche de um número crescente de detalhes, porque o desenvolvimento do esquema se faz pela absorção de todas as lembranças e de todas as imagens que este esquema pode assimilar. Assim, no esforço intelectual relativamente simples, que é a atenção dada a uma percepção, parece, como o dizíamos, que a percepção bruta começa por sugerir uma hipótese destinada a interpretá-la e que este esquema atrai a si as lembranças múltiplas que ele tenta fazer coincidir com tais ou quais partes da própria percepção. A percepção se enriquece com todos os detalhes evocados pela memória das imagens, e distingue das outras percepções pela etiqueta simples que o esquema tiver começado, de alguma maneira, a colar nela.

Foi dito que a atenção é um estado de monoideísmo. ${ }^{20} \mathrm{E}$ observou-se também que a riqueza de um estado mental é proporcional ao seu esforço. Essas duas visões são facilmente conciliáveis. Em todo esforço intelectual, há uma multiplicidade visível ou latente de imagens que se impelem e se pressionam para entrar num esquema. Mas o esquema, sendo relativamente uno e invariável, as imagens múltiplas que aspiram a preenchê-lo são ou análogas entre si ou coordenadas umas às outras. Só há, pois, esforço mental onde existem elementos intelectuais em via de organização. Nesse sentido, todo esforço mental é uma tendência ao monoideísmo. Mas, então, a unidade para a qual o espírito caminha não é uma unidade abstrata, seca e vazia. É a unidade de uma "idéia diretriz" comum a um grande número de elementos organizados. É a própria unidade da vida.

De um mal-entendido acerca da natureza desta unidade, surgiram as principais dificuldades levantadas pela questão do esforço intelectual. Não se pode duvidar de que esse esforço "concentra" o espírito e o conduz a uma representação "única". Mas do fato de uma representação ser una não

20 Ribot, Psychologie de l'attention, Paris, 1889, p.6. 
se segue que ela seja uma representação simples. Ela pode, ao contrário, ser complexa, e mostramos que há sempre complexidade quando o espírito realiza esforço, e que esta é a característica própria do esforço intelectual. Eis por que acreditamos poder explicar o esforço da inteligência sem sair da própria inteligência, por uma certa composição ou uma certa interferência dos elementos intelectuais entre si. Ao contrário, se se confunde, nesse caso, unidade e simplicidade, se se imagina que o esforço intelectual pode dirigir-se a uma representação simples e conservá-la simples, como distinguir uma representação, quando ela é trabalhosa, desta mesma representação, quando ela é fácil? Como diferenciar o estado de tensão do estado de relaxamento intelectual? Seria preciso procurar a diferença fora da própria representação. Seria preciso atribuí-la seja ao acompanhamento afetivo da representação seja à intervenção de uma "força" exterior à inteligência. Mas nem este acompanhamento afetivo nem este indefinível suplemento de força explicarão no que e por que o esforço intelectual é eficaz. No momento de dar conta da eficácia, será preciso afastar tudo o que não for representação, colocar-se em face da própria representação, procurar uma diferença interna entre a representação puramente passiva e a mesma representação acompanhada de esforço. Então, perceber-se-á, necessariamente, que esta representação é um composto e que os elementos da representação não têm, nos dois casos, a mesma relação entre si. Mas, se a contextura interior difere, porque não atribuir a essa diferença a característica do esforço intelectual? Visto que acabar-se-á sempre por reconhecer esta diferença, por que não começar por ela? E se o movimento interior dos elementos da representação dá conta, no esforço intelectual, do que o esforço tem de trabalhoso e de eficaz, como não ver neste movimento a essência mesma do esforço intelectual?

Dir-se-á que postulamos a dualidade do esquema e da imagem, ao mesmo tempo em que a ação de um dos elementos sobre o outro?

Mas, primeiramente, o esquema de que falamos não tem nada de misterioso nem mesmo de hipotético. Ele não tem também nada que possa chocar as tendências de uma psicologia habituada, senão em converter todas as nossas representações em imagens, pelo menos a definir toda representação por relação a imagens, reais ou possíveis. É em função de imagens reais ou possíveis que se define o esquema mental, tal como o consideramos em todo esse estudo. Ele consiste em uma espera de imagens, em uma atitude intelectual destinada, ora a preparar a chegada de uma certa imagem precisa, como no caso da memória, ora a organizar um jogo mais ou menos prolongado entre as imagens capazes de virem nele se inserir, como no caso da imaginação criadora. Ele é, em estado aberto, o que a imagem é, em estado fechado. Ele apresenta em termos de devir, dinamicamente, o que as imagens nos dão como acabado, em estado estático. Presente e 
agindo no trabalho de evocação das imagens, ele se apaga e desaparece por detrás das imagens evocadas, tendo realizado sua obra. A imagem com contornos determinados desenha o que foi. Uma inteligência que operasse apenas com imagens desse gênero não poderia reconstituir seu passado tal e qual ou dele tomar os elementos fixos para os recompor em uma outra ordem, por um trabalho de mosaico. Mas para uma inteligência flexível, capaz de utilizar sua experiência passada, retorcendo-a segundo as linhas do presente, seria preciso, ao lado da imagem, uma representação de ordem diferente sempre capaz de se realizar em imagens, mas sempre distinta delas. O esquema não é outra coisa.

A existência desse esquema é, pois, um fato, ao contrário da redução de toda representação a imagens sólidas, calcadas no modelo dos objetos exteriores, que seria uma hipótese. Acrescentemos que em nenhum lugar essa hipótese manifesta tão claramente a sua insuficiência quanto na questão atual. Se as imagens constituem o todo de nossa vida mental, no que o estado de concentração do espírito poderia se diferenciar do estado de dispersão intelectual? Seria preciso supor que em certos casos elas se sucedem sem intenção comum, e que em outros casos, por um inexplicável acaso, todas as imagens simultâneas e sucessivas se agrupam de modo a dar a solução cada vez mais aproximada de um único e mesmo problema. Dir-seá que não é um acaso, que é a semelhança das imagens que faz com que elas evoquem umas às outras, mecanicamente, segundo a lei geral de associação? Mas, no caso do esforço intelectual, as imagens que se sucedem podem justamente não ter nenhuma similitude exterior entre si: sua semelhança é toda interior. É uma identidade de significação, uma igual capacidade de resolver um certo problema face ao qual elas ocupam posições análogas ou complementares, a despeito de suas diferenças de forma concreta. É preciso, pois, que o problema seja representado ao espírito e não sob a forma de imagem. Sendo ele mesmo imagem, evocaria imagens semelhantes a ele e semelhantes entre si. Mas visto que seu papel é, ao contrário, o de evocar e de agrupar as imagens segundo seu poder de resolver a dificuldade, ele deve dar conta desse poder das imagens, não de sua forma exterior e aparente. É, portanto, um modo de representação distinto da representação por imagem, embora só possa se definir em relação a ela.

Em vão se objetaria alegando a dificuldade de se conceber a ação do esquema sobre as imagens. A ação da imagem sobre a imagem é mais clara? Quando se diz que as imagens se atraem em razão de sua semelhança, vaise além da constatação pura e simples do fato? Tudo o que pedimos é que não se negligencie nenhuma parte da experiência. Ao lado da influência da imagem sobre a imagem, há a atração ou impulsão exercida sobre as imagens pelo esquema. Ao lado do desenvolvimento do espírito em um único plano, em superfície, há o movimento do espírito de um plano a outro, em 
profundidade. Ao lado do mecanismo de associação, há o do esforço mental. As forças que trabalham nos dois casos não diferem simplesmente pela intensidade, elas se diferem pela direção. Quanto a saber como elas trabalham, é uma questão que não é só da alçada da psicologia: ela se liga ao problema geral e metafísico da causalidade. Entre a impulsão e a atração, entre a causa "eficiente" e a "causa final", há, acreditamos, algo intermediário, uma forma de atividade de onde os filósofos tiraram, pela via do empobrecimento e da dissociação, passando aos dois limites opostos e extremos, a idéia de causa eficiente, por um lado, e a de causa final, de outro. Esta operação, que é a própria operação da vida, consiste em uma passagem gradual do menos realizado ao mais realizado, do intensivo ao extensivo, de uma implicação recíproca das partes à sua justaposição. O esforço intelectual é alguma coisa desse gênero. Analisando-o, cercamos o mais perto que pudemos, com o exemplo mais abstrato e, conseqüentemente, mais simples, esta materialização crescente do imaterial que é característica da atividade vital.

Tradução recebida em 06/05; aprovada para publicação em 01/06. 